\title{
Evaluation of Flexible Pavement Reinforced with Geosynthetics using Static and Dynamic Loading Tests
}

\author{
Alaa M. Ali \\ Ph.D., Assistant Professor, Civil Engineering Dept. \\ Misr High Institute for Engineering \& Technology, \\ Mansoura, Egypt.
}

\begin{abstract}
The CBR test has been approved to be useful in evaluating reinforced subgrade soils. When testing specimens after soaking with and without reinforcement, one can procure two values of CBR for comparison. However, the need to evaluate reinforced subgrade soils under loading conditions similar -as possible- to those in field is warranted. The key intention of this research is to study the improvements of pavement matrix life cycle when reinforced by geosynthetics. For this purpose, four testing pavement groups were constructed to replicate the real existing field conditions as possible. One group was the control section while the other three were reinforced with geotextiles and geonets. Simulated traffic repeated loads were applied on the matrices while corresponding vertical deformations of pavements surface were measured at loading plate edge. It was concluded that testing relatively larger scale models by repeated loading is more realistic than by CBR test. In addition, geonets perform better than geotextiles when used as reinforcement.
\end{abstract}

Index Terms; Reinforced pavement, Geosynthetics, repeated loading test, CBR test

\section{INTRODUCTION}

In flexible pavement design, subgrade vertical deformation is considered one of the major failure distresses. Recent design changes have been brought by heavy wheel loads and higher traffic levels. The effect of environmental conditions during the year on subgrade properties initiates faster propagation of pavement deformation. Chemical stabilization of weak subgrades, thicker pavements thickness or subgrade reinforcement are some alternatives adopted for reducing pavement vertical deformation. Geosynthetics have been recognized as material that can develop the performance of highway pavements, particularly those constructed on weak soils. Geotextiles, geonets, geogrids and geocomposits are types of well-known geosynthetics. Geotextiles consist of synthetic threads that are produced by either a woven or a non-woven way. Geogrids and geonets are fabricated from polypropylene or high tenacity polyester [4].

The basic function of geotextiles in improving pavement's performance is known as separation, filtration and sometimes reinforcement. Geogrids and geonets are considered mainly as reinforcing members. However, geocomposits are believed to successfully act as separator, reinforcement and filler.

Numbers of laboratory studies have indicated that geosynthetics reinforcement improves the performance of flexible pavement by savings either in base course thickness or in expanding the service life. Despite the good laboratory proof for the flexible pavement reinforced with geosynthetics, the mechanism that enables and governs the reinforcement function is still unclear [3].

When a pavement system is reinforced, wheel load is distributed over a larger area of subgrade-base interface As shown in figure-1. The result will be lower vertical stress and deformation of subgrade surface. To achieve a better distribution of wheel load, a certain vertical deformation must be reached [2]. This vertical deformation is required together with enough friction between subgrade-geosynthetic-base interfaces to produce the uplift load of reinforcing material. If geosynthetics has enough tensile resistance, the subgrade vertical deformation may be controlled.

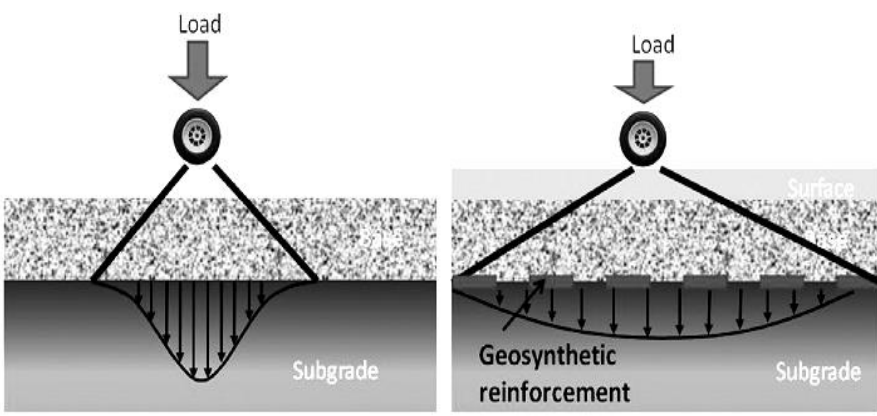

Figure-1: Relative load distribution at subgrade-base interface for reinforced and un-reinforced flexible pavement

Therefore, subgrade stabilization by reinforcement is more pronounced for weak soils (to initiate enough vertical deformation) even it is requires enough pavement thickness (to act as surcharge load for interface-friction production). It is believed that a successful design is that satisfies the balance between these two constrains. Some researches concluded that the geotextiles effectiveness is significant when deformation was increased and suggested that "the higher the tensile moduli of fabrics as measured by the modulus of secant, (i.e. the tensile force in $\mathrm{KN} / \mathrm{m}$ divided by corresponding strain in $\mathrm{mm}$ ), the larger the amount of subgrade strengthening achieved" [1]. Other researches concluded that the benefits of geotextiles are derived from their separation and filtration characteristics [3].

\section{TESTING PROGRAM}

The performance of flexible pavements reinforced with geosynthetics can be evaluated by using laboratory tests, field tests or numerical simulations. These three practices not only 
differ widely, but also present different views on performance.

The testing program in this study was conducted at the highway engineering and soil research laboratory, faculty of engineering.

The program enclosed two phases; the first, included the routine testing of materials including subgrade, base and geosynthetics characteristics of materials such as gradation, maximum dry density and optimum moisture content(OMC), specific gravities, California Bearing Ratio (CBR) values. Physical and tensile properties of geosynthetics were also evaluated. In addition, the CBR values of compacted subgrade soil prior and past to soaking upon reinforcement with different types of geosynthetic were determined. The second phase comprised testing the subgrade soil as a part of pavement section inside a testing model simulating the field condition before and after reinforcement.

Four different pavement sections were constructed in specially manufactured steel moulds. One test section was un-reinforced, control section; two test sections were reinforced with textiles and the fourth was reinforced with a geonets.

Following the construction of each section, the pavement surface was repeatedly loaded by a rigid plate, at the same time; the surface rutting was measured using mechanical sensitive dial gauges. The components and methods of constructing test sections are summarized below.

\section{Testing Equipments}

CBR Testing: The CBR Experiments were carried out in a modified mould of $300 \mathrm{~mm}$ diameter and $175 \mathrm{~mm}$ height with a collar of $50 \mathrm{~mm}$. A specially designed upper ring was manufactured to anchor the reinforcement. The schematic of the tested reinforced matrix is as illustrated in figure-2

Repeated Loading Testing: A rigid steel mould with $350 \mathrm{~mm} x$ $350 \mathrm{~mm}$ cross-section and $500 \mathrm{~mm}$ height as shown in figure-3 was manufactured for pavement section inclusion. The mould was provided with a sidehinged door to allow soil removal. The door had two locks for tightening in place during compaction and testing. Mould joints were carefully sealed to prevent any leakage of water. The subgrade material was compacted manually using the modified proctor hammer in seven layers of $40 \mathrm{~mm}$ thickness. Before compaction, soil was water mixed carefully with predetermined moisture content.

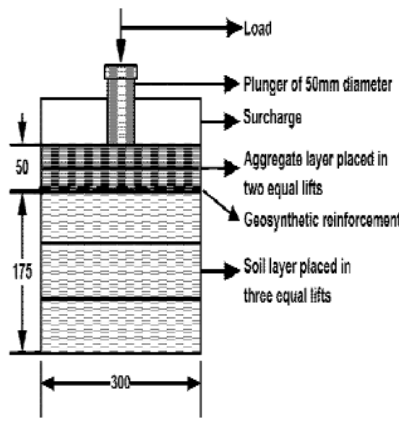

Figure-2: Schematic of modified CBR Reinforced Soil-Aggregate matrix

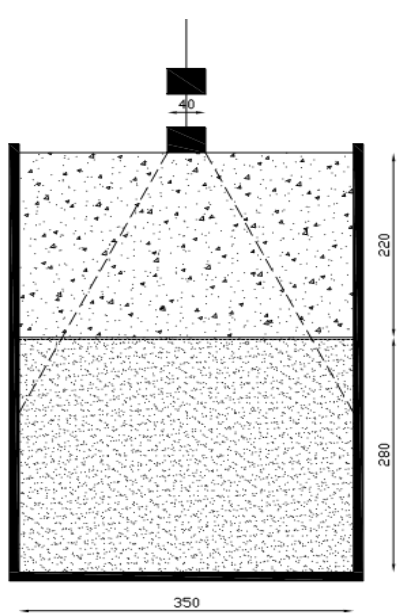

Figure-3: Schematic of repeated load Reinforced Soil-Aggregate matrix mould
Compaction was then continued until a known batch weight filling a pre-set volume to achieve the required maximum wet density. The same approach was followed in base layer compaction overlaying the rest of $500 \mathrm{~mm}$ height. The system was prepared to allow measuring base surface deflections using sensitive dial gauges. A steel frame provided with steel hammer was employed to apply the repeated load. Weight of dropping hammer and height of drop were adjusted to apply a surface stress representing dual-tire loading of an $80 \mathrm{kn}$ $(18,000 \mathrm{Ib})$ axle. The dropping load was repeated using an electric motor and speed controller system similar to that of the mechanical proctor compactor. The loading calibration revealed that a drop weight of $3.5 \mathrm{~kg}(34 \mathrm{~N})$ with drop height of $40 \mathrm{~mm}$ and a circular loading base of $40 \mathrm{~mm}$ diameter were needed for applying a surface stress of $0.05 \mathrm{~kg} / \mathrm{cm}^{2}(73 \mathrm{psi})$. The loading frequency was about $80 \mathrm{RPM}(1.3 \mathrm{~Hz})$.

\section{Testing Materials}

The control test sections consisted of a compacted silty-sand subgrade and well-graded sandy-gravel base course. For the three reinforced sections, geotextiles and geonet was located at the base-subgrade interface. Characteristics of the testing materials are illustrated in the following sections.

\section{Subgrade soil;}

The subgrade soil was fine poorly graded silty-sand classified as A-3 type according to AASHTO classification system; it was obtained from Egypt north-coast near Port-Saied. NonPlastic fines content was $83 \%$, the specific gravity was 2.747 and the maximum dry density was 1.759 at an OMC of $12.3 \%$.

\section{Base course}

A sandy gravel soil was used as a base course in the testing model. The gradation of the base course aggregate met the grade-D specification of AASHTO soil aggregate mixture. The modified proctor maximum dry density was $2.36 \mathrm{t} / \mathrm{m}^{3}$ at an optimum water content of $6.5 \%$.

\section{Reinforcing materials;}

One geonet (type-1) was selected for testing. It had $11 \mathrm{~mm}$ by $11 \mathrm{~m}$ aperture size, $3.1 \mathrm{~mm}$ thickness and average weight of $728 \mathrm{gm} / \mathrm{m}^{2}$. Two types of geotextiles were selected to be evaluated. The first, (type-2) had a woven structure of $3 \mathrm{~mm}$ by $2 \mathrm{~mm}$ aperture size with a $0.44 \mathrm{~mm}$ nominal thickness and average weight of $63.5 \mathrm{gm} / \mathrm{m}^{2}$. The second, (type-3) had also woven structure with $2 \mathrm{~mm}$ by $0.2 \mathrm{~mm}$ aperture. Its nominal thickness was $0.2 \mathrm{~mm}$ and its weight was $70 \mathrm{gm} / \mathrm{m}^{2}$. All geosynthetics thicknesses were measured unloaded; i.e. at zero overburden pressure. Also, the three reinforcing materials were stored and experimented at room temperature $\left(25 \pm 2^{\circ} \mathrm{C}\right)$.

The wide-width tensile strength of different reinforcing materials has been measured and computed at textile engineering department, faculty of engineering, employing the Italian (ENEL) standard equation at different strain levels[1] and are given in Table-1. Other routine testing of geosynthetics such as degradation resistance with time, puncture resistance, chemicals resistance and temperature change resistance were out of scope of this study. 
Table-1: Computed wide-width tensile strength of reinforcement.

\begin{tabular}{|c|c|c|c|c|}
\hline & \multicolumn{4}{|c|}{ Wide-Width Tensile Strength } \\
\hline Type of Rnft. & $\begin{array}{c}1 \% \text { strain } \\
(\mathrm{N} / \mathrm{cm})\end{array}$ & $\begin{array}{c}2 \% \text { strain } \\
(\mathrm{N} / \mathrm{cm})\end{array}$ & $\begin{array}{c}5 \% \text { strain } \\
(\mathrm{N} / \mathrm{cm})\end{array}$ & $\begin{array}{c}\text { Ultimate } \\
(\mathrm{N} / \mathrm{cm})\end{array}$ \\
\hline Geonet (type-1) & 11.3 & 12.6 & 11.0 & 12.5 \\
\hline Geotextile (type-2) & 5.4 & 7.0 & 9.0 & 13.0 \\
\hline Geotextile (type-3) & 8.6 & 11.5 & 14.4 & 14.7 \\
\hline
\end{tabular}

\section{CBR Testing Procedures}

The obtained CBR values at different moisture content of subgrade soil were as scheduled in Table- 2 .

Table-2: Effect of Moisture Content on Subgrade CBR value

\begin{tabular}{|l||c||c||c||c||c|}
\hline \% Moisture Content & 5.5 & 7.0 & 12.3 & 14.5 & 18.0 \\
\hline \hline$\%$ CBR & 15 & 25 & 31 & 20 & 4 \\
\hline
\end{tabular}

The CBR values of subgrade with and without reinforcement employing the three types of geosynthetics are as in Table-3

Table-3: CBR values for different cases

\begin{tabular}{|c||c|c||c|c|c||}
\hline \multirow{2}{*}{ Case } & \multicolumn{2}{|c|}{ Without Rnft } & \multicolumn{2}{|c|}{ With Rnft after soaking } \\
\cline { 2 - 6 } & at OMC & After soaking & \multicolumn{1}{|c|}{ Tvpe-1 } & Tvpe- 2 & Tvpe-3 \\
\hline \hline \% CBR & $\mathbf{3 1}$ & $\mathbf{4}$ & $\mathbf{2 0}$ & $\mathbf{9}$ & $\mathbf{8}$ \\
\hline
\end{tabular}

\section{Repeated Load Testing Procedures}

For characterizing the behavior of geosynthetics reinforcement in flexible pavements, repeated loading test has been successfully verified the effect of soil confinement and dynamic loading. In this study, the test was run on four different groups of pavement sections. One group was prepared without reinforcement and each of the other three groups contained a layer of reinforcement known as type-1, type- 2 and type- 3 between the subgrade-base interface. In the control subgroup (un-reinforced), base thickness and subgrade moisture content were varied at three levels. In other words, sections of subgrade moisture content at $12.3 \%$, $16.0 \%$ and $18 \%$ were prepared for each case of base-course thickness of $50 \mathrm{~mm}, 100 \mathrm{~mm}$, and $150 \mathrm{~mm}$ then tested. For reinforced sections, the subgrade moisture content was set at two levels only, i.e. at optimum moisture content (12.3\%) and at soaking condition $(18.0 \%)$. After preparing a test section, the loading was applied on the base surface whilst the displacement at the pavement surface near the edge of the loading plate were recorded after 40, 80, 320, 640, 960, 1200, 1500,1800 and 2100 cycles of load. After finishing one test, the testing mould was carefully excavated. The pavement was cut along the centerline and the materials were evacuated from the front door of the mould. The condition of the final base and subgrade were visually recorded.

\section{TEST RESULTS AND ANALYSIS}

\section{CBR test evaluation}

Load-Penetration relationship for types 1, 2 and 3 are illustrated in figure- 4 using the same testing plunger and loading rate of standard CBR test.

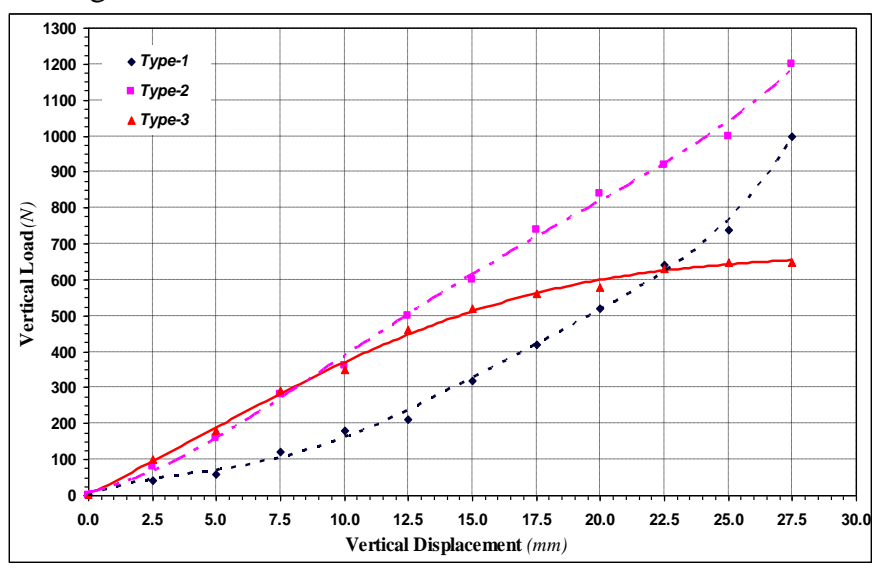

Figure-4: Load-Displacement correlation for the three types of Geosynthetics in CBR test

When subgrade soil is rested at optimum moisture content, it can be considered as excellent subgrade since the CBR is 31 as can be seen in table-1. However, when soil is soaked, reflecting the case of soaring ground water table and bad surface and subsurface drainage, the CBR is reduced to 4 . None of the three types of geosynthetics employed in this study have succeeded in upgrading the CBR of the subgrade to its maximum value; i.e. CBR at OMC as shown in table-3. In other words, reinforcing soaked subgrade has raised its CBR value from 4 to 20,9 and 8 for type-1, type- 2 and type3 respectively. It is believed that the larger the width of opening, and the greater the reinforcement thickness lead to mobilize enough friction interlock between base and subgrade soil to produce an upward resistance to balance the acting vertical load and result in larger CBR value; (i.e. 20 against 3 ). The other two geotextiles had not enough friction fixations to produce the same high upward reaction.

\section{Repeated loading test evaluation}

Performance of testing section was evaluated to study the effect of repeated loading on pavement displacement for the following conditions;

1. Un-reinforced pavements on subgrade soil prepared at three different moisture contents; 12.3, 16.0 and 18.0.

2. Reinforced pavements on subgrade soil at its weakest and best conditions; i.e., soaking moisture content and OMC.

3. For the above conditions, pavement thickness was varied. Effect of Subgrade moisture;

A typical relationship between surface rutting and load repetitions number for un-reinforced sections are presented in figures 5, 6 and 7. In all figures, the surface rutting (displacement) increased with increasing the repetitions number. However, the rate of displacement decreased.

A great proportion of the total surface rutting after 2000 load repetitions occurred shortly after test beginning. The thicker the pavement the larger the load repetitions number needed to produce $50 \%$ of the final displacement. The thicker the 
pavement, the smaller the subgrade settlement and the larger the pavement displacement.

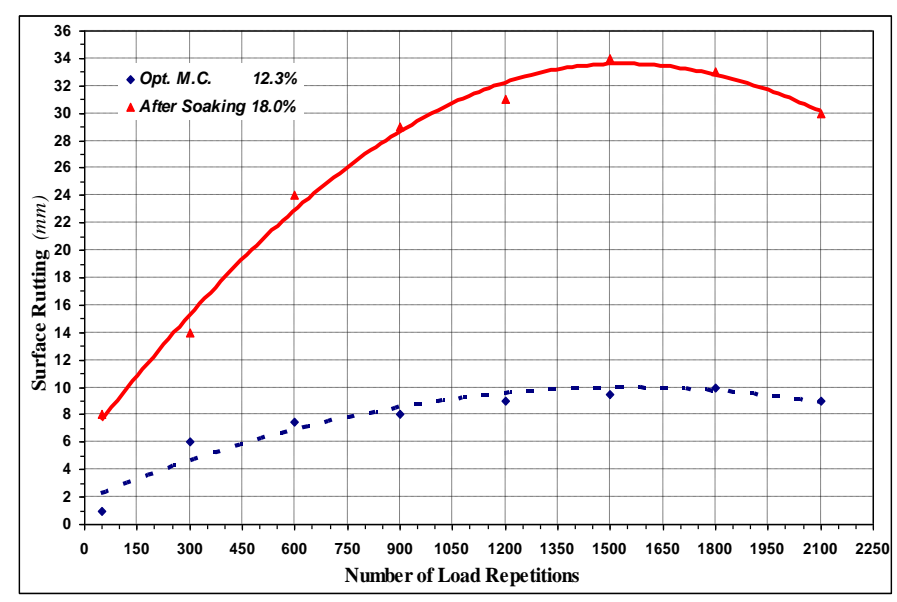

Figure-5: Effect of subgrade moisture content on surface rutting without reinforcement $($ Base course $=50 \mathrm{~mm}$ )

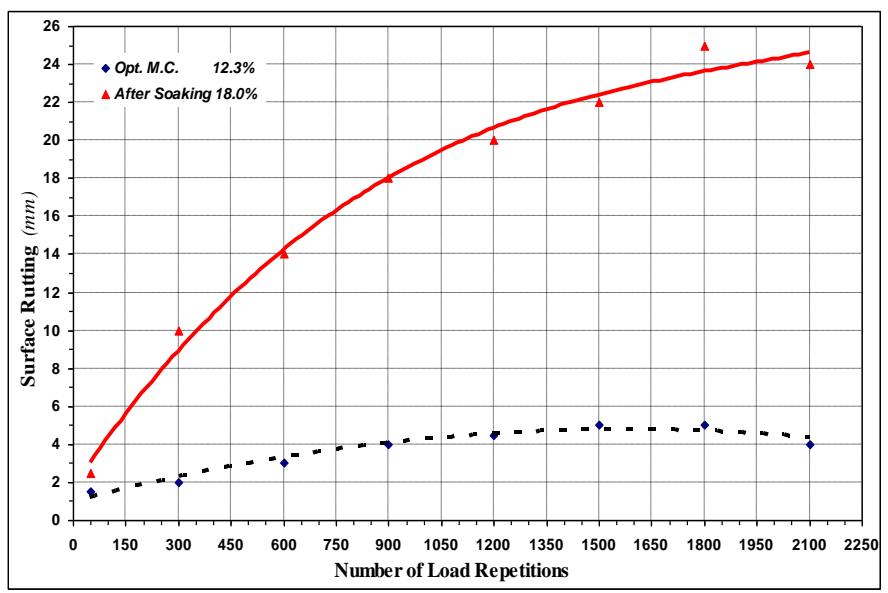

Figure-6: Effect of subgrade moisture content on surface rutting without reinforcement (Base course $=100 \mathrm{~mm}$ )

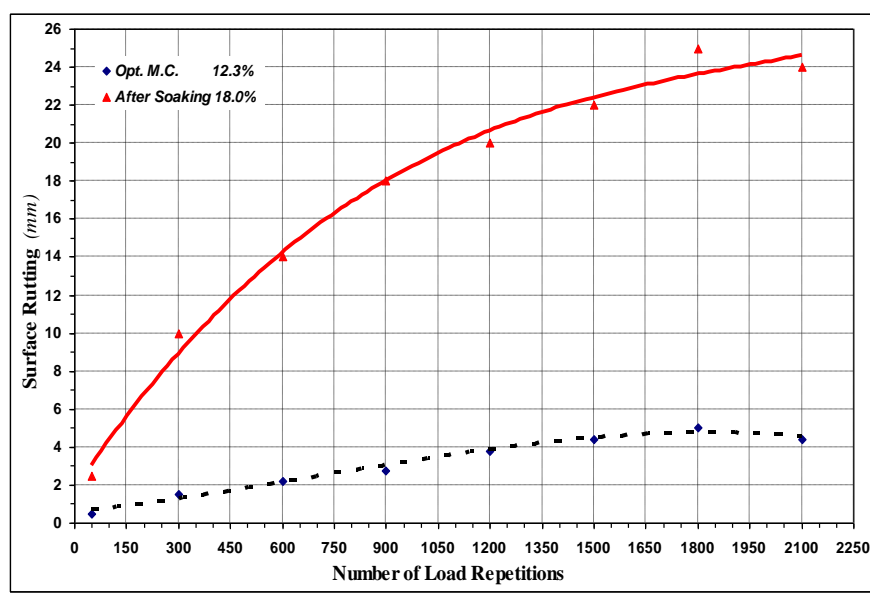

Figure-7: Effect of subgrade moisture content on surface rutting without reinforcement (Base course $=150 \mathrm{~mm}$ )

As shown in above figures, the wetter the moisture contents of subgrade from optimum, the larger the surface rutting. The total surface rutting for subgrade after soaking was about 3.0, 5.0 and 5.5 times that at OMC for 50, 100 and $150 \mathrm{~mm}$ base thickness respectively. Theses figures clarify the moisture sensitivity of that type of subgrade soil (silty sand) to moisture saturation. In addition, for the three cases of subgrade moisture the thicker the pavement thickness, the lower the surface rutting (displacement). For example, after 2000 load repetitions, pavement surface rutting on subgrade after soaking was $32 \mathrm{~mm}, 25 \mathrm{~mm}$ and $11 \mathrm{~mm}$ for base thickness of $50 \mathrm{~mm}, 100 \mathrm{~mm}$ and $150 \mathrm{~mm}$ respectively.

Effect of subgrade reinforcement;

Same observation, as for control section, related to large values of initial displacement and the decrease in rate of displacement by time are experienced when testing reinforced subgrade. In general, a relatively slight improvement in surface rutting is achieved when a layer of reinforcement is introduced between subgrade at OMC; the improvement is less than that at soaking condition. Comparing figure- 8 to figure-9.

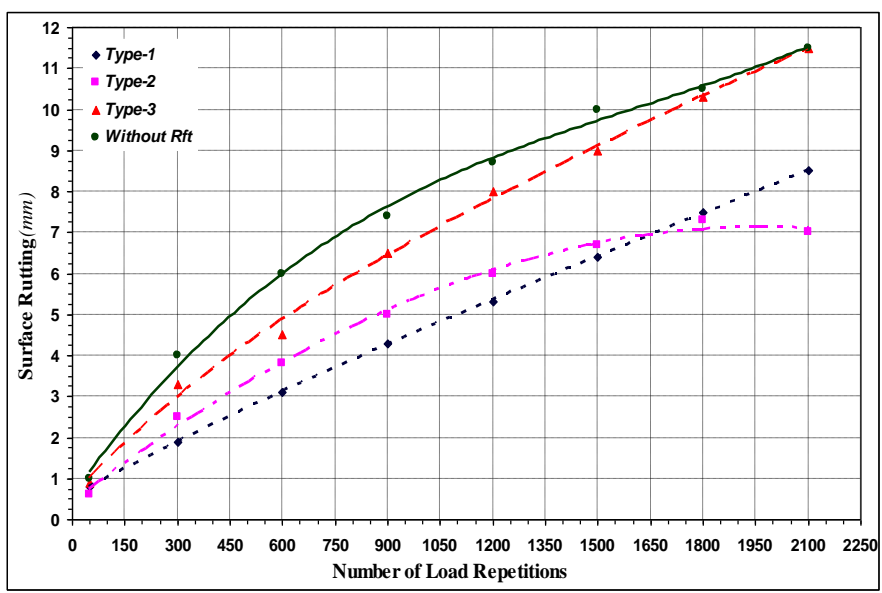

Figure-8: Effect of type of reinforcement on progressive surface rutting for subgrade at OMC (Base course $=50 \mathrm{~mm})$

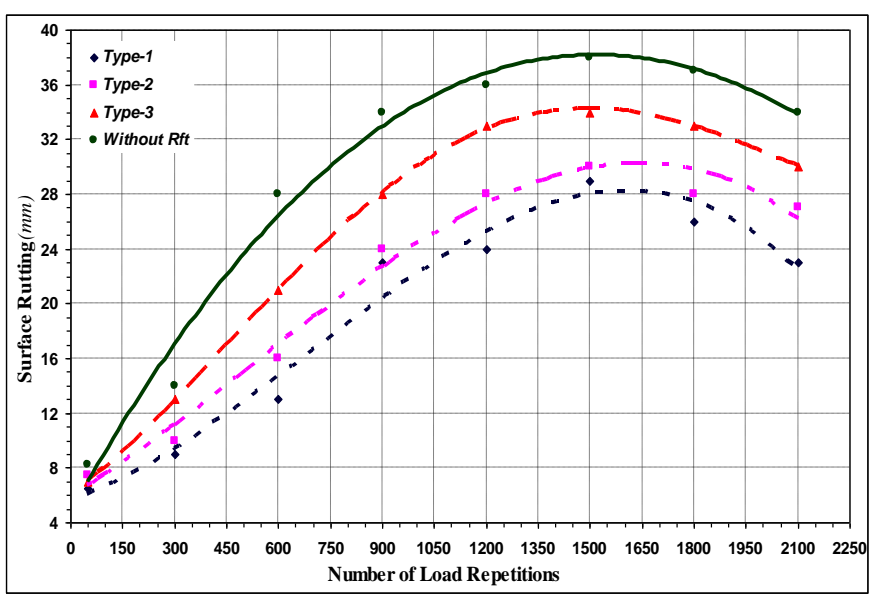

Figure-9: Effect of type of reinforcement on progressive surface rutting for subgrade at soaking condition (Base course $=50 \mathrm{~mm}$ )

When subgrade was at weaker condition; (i.e. after soaking), the effect of reinforcement was more pronounced as illustrated in figure-9, especially when larger of load repetitions number increased. In this figure, and for a pavement thickness of 50mm, surface rutting after 2000 load repetitions when employing a geonet (type-1) was $24 \mathrm{~mm}$ 
compared to $35 \mathrm{~mm}$ when un-reinforced. The other two geotextiles reduced surface rutting to $28 \mathrm{~mm}$ for type- 2 and $31 \mathrm{~mm}$ for type-3 after 2000 load repetitions.

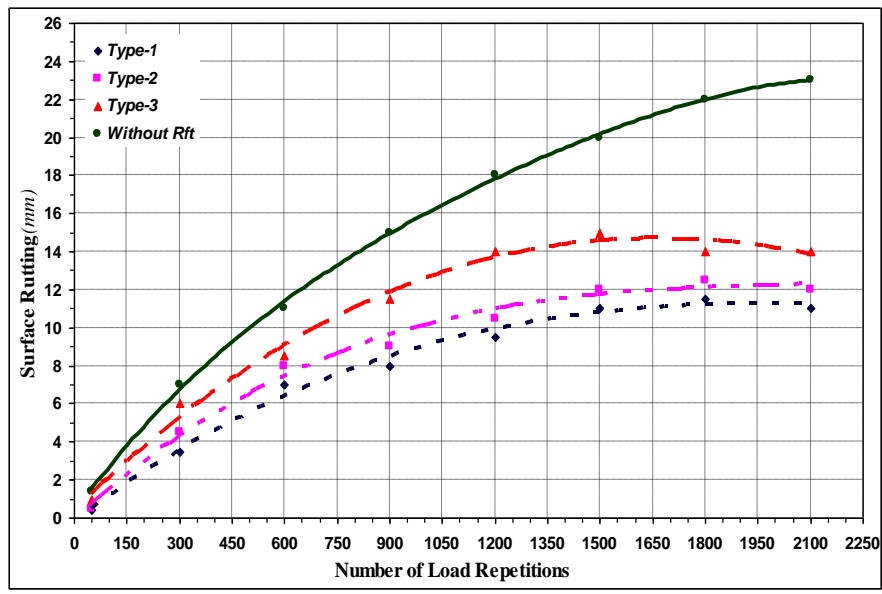

Figure-10: Effect of type of reinforcement on progressive surface rutting for subgrade at soaking condition (Base course $=100 \mathrm{~mm}$ )

When pavement thickness was increased to $100 \mathrm{~mm}$, a better improvement in surface rutting was gained. Although the three times of reinforcements acted almost equally a greater reduction in surface deformation is achieved. As illustrated, in figure-10, base course was $100 \mathrm{~mm}$, the effect of reinforcement was more pronounced after larger number of load repetition. At 2000 load repetitions, the surface displacement for un-reinforced pavement was $23 \mathrm{~mm}$ compared to $11-14 \mathrm{~mm}$ for a reinforced one.

Generally, a geosynthetic layer between subgrade and base facilitated better distribution of surface load resulting in lower displacement of subgrade [3]. In figure-9, for a base of $50 \mathrm{~mm}$ thickness, when surface rutting for the control section was $27 \mathrm{~mm}$ after about 600 load repetitions, employing any of the three types of geosynthetics reduced surface rutting to 70 $80 \%$ of control section value.

After 2000 load repetitions, the reduction was 75-90\%. Moreover, when base thickness was $100 \mathrm{~mm}$, surface rutting was reduced to about $40 \%$ of control section value after 2000 load repetitions, this may be because of the better friction between reinforcing material and subgrade achieved from bigger surcharge load of thicker pavement.

Comparing figures 6 and 9, one can observe that surface rutting of un-reinforced $100 \mathrm{~mm}$ base is lower than that of reinforced $50 \mathrm{~mm}$ base pavement up to 2000 load repetitions. May be if test had been extended after that number of repetitions, a geonet reinforcement would have provided better performance.

The same observations pertain when comparing un-reinforced $150 \mathrm{~mm}$ base to reinforced $100 \mathrm{~mm}$ base, as shown in figures 7 and 10. After 2000 load repetitions, surface rutting of unreinforced $150 \mathrm{~mm}$ base is $12 \mathrm{~mm}$ while it was $11 \mathrm{~mm}, 12 \mathrm{~mm}$ and $14 \mathrm{~mm}$ for $100 \mathrm{~mm}$ base with type- 1 , type- 2 and type- 3 reinforcement respectively.

\section{CONCLUSIONS}

Based on the materials used, data available and testing method followed, the following can be concluded;

1. Evaluating reinforcing geosynthetics materials in highway applications through applying static type of testing, i.e. CBR test could be misleading.

2. The performance of geosynthetics materials under repeated load testing, which simulate the actual loading condition, is found to be more realistic. However, both dynamic and static tests are recommended.

3. A geonet is found to be better than geotextiles as a reinforcing material. A geotextiles may act mainly as separation layer in a pavement system.

4. Improving the drainage quality of a subgrade soil, provide better improvement in reducing surface rutting than employing an additional layer of reinforcement.

5. Cost comparison study must be considered in a decisionmaking of using geosynthetics against other pavement improvement alternatives.

\section{REFERENCES}

[1] De Gardiell, R . and E javor, "Mechanical reinforcement of low volume roads by geotextiles" proc. $3^{\text {rd }}$ International conference on geotextiles. Vienna, Austria. 2006.

[2] Giroud J.P. and I. Noiray "Geotextiles reinforced unpaved road design" Journal of the geotechnical engineering division, ASCE, Sep 2011 pp1233.

[3] G.S.Ingle and S.S.Bhosale "Geosynthetics reinforced flexible pavement". International Journal of Engineering \& Technology, 6 (4) (2017) pp103-107.

[4] Koerner, R "Designing with geosynthetics, $2^{\text {nd }}$ Edition, Prentice hall, Englewood cliffs, N.J. USA, 2012.

[5] Resl, S. and G wener "the influence of Non-woven needle punched geotextiles on the ultimate bearing capacity of the subgrade'. Proc. "The $3^{\text {rd }}$ International conference on geotextiles". Vienna, Austria. 2006

\section{AUTHOR BIOGRAPHY}

Dr. Alaa M. Ali , obtained his doctorate degree from Faculty of Engineering, Mansoura University, Egypt. Now he is assistant professor of highways engineering at Misr High Institute for Engineering and Technology, Mansoura, Egypt. He has over eight publications including highways materials, evaluation and roads maintenance 